\title{
AC 2012-4351: ENGINEERING FACULTY ENGAGEMENT IN LEARN- ING THROUGH SERVICE SUMMIT: BEST PRACTICES AND AFFINITY MAPPING
}

\author{
Dr. Angela R. Bielefeldt, University of Colorado, Boulder
}

Angela Bielefeldt has been a professor in the Department of Civil, Environmental, \& Architectural Engineering at the University of Colorado, Boulder, since 1996. She has taught first-year introductory courses, senior capstone design, and specialty senior-level/graduate courses in environmental engineering. Her research interests in engineering education have focused on service learning, sustainability, and ethics.

\section{Prof. Kurt Paterson P.E., Michigan Technological University}

Kurt Paterson, Associate Professor of civil and environmental engineering, is also Director of Michigan Tech's D80 Center. D80 has the mission to develop contribution-based learning, research, and service opportunities for all students and staff to partner with the poorest $80 \%$ of humanity, together creating solutions that matter. As Director of several international programs at the undergraduate and graduate levels, Paterson, his colleagues, and his students have conducted numerous community-inspired research and design projects. Paterson is an educational innovator, recently adding courses for first-year students, Great Ideas, and graduate students, Discover Design Delight. At the intersection of these two fields, Paterson leads several national initiatives for learning engineering through service, recently taking the reins for the American Society for Engineering Education's newest Division startup, Community Engagement in Engineering Education. He is PI, or Co-PI, on several large projects assessing the impacts of learning through service on students, faculty, and communities around the world.

\section{Dr. Chris Swan, Tufts University}

Chris Swan is an Associate Professor of civil and environmental engineering with additional appointments in the Jonathan M. Tisch College of Citizenship and Public Service and the Center for Engineering Education and Outreach at Tufts University. He has served as Chair of Tufts CEE Department (2002-2007) and has been active in the ASEE since 2001, currently serving as the Program Chair for the Community Engagement in Engineering Education constituent committee. Swan's current research interests in engineering education concern project-based learning and service-based pedagogy.

\section{Dr. John J. Duffy, University of Massachusetts Lowell \\ Dr. Olga Pierrakos, James Madison University}

Olga Pierrakos is an Associate Professor and founding faculty member in the School of Engineering, which is graduating its inaugural class May 2012, at James Madison University. Pierrakos holds a B.S. in engineering science and mechanics, an M.S. in engineering mechanics, and a Ph.D. in biomedical engineering from Virginia Tech. Her interests in engineering education research center around recruitment and retention, engineering design instruction and methodology, learning through service (NSF EFELTS project), understanding engineering students through the lens of identity theory (NSF BRIGE grant), advancing problem-based learning methodologies (NSF CCLI grant), assessing student learning, and understanding and integrating complex problem solving in undergraduate engineering education (NSF CAREER grant). Her other research interests lie in cardiovascular fluid mechanics, sustainability, and K-12 engineering outreach.

\section{Nathan E. Canney, University of Colorado Boulder}

Nathan Canney received bachelor's degrees from Seattle University in civil engineering and applied mathematics. After graduation, he worked for Magnusson Klemencic Associates in Seattle, Wash., as a structural engineer on high-rise residential buildings. Canney returned to school at Stanford University for a master's degree and is currently pursuing a doctoral degree at the University of Colorado, Boulder, in civil engineering, with an engineering education research focus. 


\title{
Engineering Faculty Engagement in Learning Through Service Summit: Best Practices and Affinity Mapping
}

\begin{abstract}
A workshop was held in 2011 with the goal of determining the best practices, benefits, and challenges of engaging in Learning Through Service (LTS) activities, with a focus on the engineering faculty perspective. LTS in engineering typically takes two forms: (1) course-based service-learning (SL) projects for real communities or individuals (such as assistive technology devices), and (2) service projects conducted via extracurricular activities such as Engineers Without Borders (EWB). Studying both of these distinct but related activities was of interest since extracurricular service activities such as EWB projects have sometimes moved into engineering courses such as capstone design. The group of engineering faculty and LTS researchers first described what excited them about LTS. Then the group shared ideas on best practices, benefits, and obstacles of LTS design, LTS management, and LTS assessment from the perspective of engineering faculty, the university, students, and communities. This paper focuses on the faculty perspective. These ideas will help faculty engaging in LTS to most effectively design and assess these activities.
\end{abstract}

\section{Introduction}

The faculty perspective with respect to engagement in Learning Through Service (LTS) activities is a critical source of information to obtain and address if LTS is to become a wider implemented teaching methodology. To this end, a summit was convened to engage a diverse sample of faculty and administrative members who are all actively engaged in LTS activities at their respective institutions. These faculty members were asked to discuss their personal motivation for engaging in LTS as well as to examine the best practices, benefits and pitfalls of different aspects of LTS, including design, management and assessment. The results of these conversations are presented in this study. In summary, the summit participants overwhelmingly cited student benefits as their motivation for engaging in LTS activities. The summit participants highlighted programmatic best practices in thedesign of LTS activities such as providing rewards for faculty, engaging with community partners and aligning LTS activities with course learning objectives. With respect to managementpractices, the summit members discussed how LTS activities can be used to strengthen student attitudes towards engineering service and altruism. The summit participants frequently mentioned the need for university support and additional resources to help encourage faculty members to engage in LTS activities which can have significant personal and professional benefits. Finally, there was consensus that there is room to grow with respect to the development of effective and relevant assessment tools for LTS activities and that these tools will help bolster facultyengagement and support for LTS involvement in the future.

\section{Background}

Learning Through Service (LTS) is a student-centered pedagogy where the objectives of student learning are balanced with real, positive impacts for a community partner. ${ }^{1}$ LTSencompasses both curricular service-learning (SL) and extracurricular activities with significant learning outcomes 
(such as working on a design project for Engineers Without Borders). There are some common issues for these activities, as well as very unique attributes of these two different forms of LTS. SL has a well-established history, with significant research on its efficacy outside of engineering. ${ }^{2}$ Engineers adoption of SL into courses typically takes the form of project based learning (PBL), as with the EPICS (Engineering Projects in Community Service) program that began at Purdue University. ${ }^{3}$ There are many examples of SL integrated into courses ranging from first year engineering projects through capstone design, and somewhat fewer examples of SL used to teach core engineering science principles. ${ }^{4,5}$ An exemplar for programmatic infusion of SL is the SLICE program at the University of Massachusetts - Lowell (UML), where the goal is for students in all engineering majors to encounter SL in one or more courses in every year of their undergraduate degree. ${ }^{6}$

On the extracurricular side of LTS, Engineers Without Borders (EWB) is the prime exemplar. From its inception as a student chapter at the University of Colorado Boulder in 2000, interest in this group has exploded. The growth to about 190student chapters at universities around the country (and more internationally) has been largely driven by students from bottom-up demand rather than top-down administration or faculty leadership. ${ }^{7}$ From its inception, EWB has put student learning and community service as equally important goals. In some cases, EWB projects have formed the basis for course-projects; i.e. capstone design projects in civil and environmental engineering at the University of Colorado Boulder and other universities. ${ }^{8}$ Other engineering service-based groups include Engineers for a Sustainable World (ESW), Bridges to Prosperity, and Habitat for Humanity.

Research has shown that different LTS activities can successfully meet a variety of learning objectives for engineering students. ${ }^{9}$ These learning goals encompass all of the ABET criterion $\mathrm{C}$ "A to K" outcomes ${ }^{10}$;in particular, some of the harder to achieve and evaluate professional skills. LTS often results in greater student motivation for learning, and a variety of attitude changes. ${ }^{11}$ In addition, LTS may help attract and retain a greater diversity of students in engineering. ${ }^{12,13}$

To allow more students to reap the benefits from LTS, faculty must be willing to integrate SL into their courses and mentor extracurricular LTS activities. However, little is known about the best practices, benefits, and challenges of LTS from an engineering faculty perspective. Results from the few studies on faculty to date are summarized below.

The SLICE program at UMLhas conducted assessment of faculty via both an annual written survey instrument and in-depth interviews with 14 faculty. ${ }^{14}$ The reach of this program has been phenomenal, growing from a single faculty member engaged in SL in 2003 to 37 of 70 faculty who teach undergraduate courses using SL. The data showed a general increase in positive attitudes toward SL among the faculty over time (2004 to 2009), and that students learned the subject matter better through SL, meeting the course learning objectives. ${ }^{15}$

Banzaertet al. ${ }^{16}$ studied mechanical engineering faculty views of SL at MIT using a 10-minute short interview method. While $80 \%$ of the faculty were open to the use of SL, $52 \%$ were concerned about time constraints and 56\% needed support to identify SL projects appropriate for the core technical course that they were teaching. SL was considered most appropriate for 
design classes. In contrast, Fontenot ${ }^{17}$ reported engineering faculty resistance to integrating SL into courses at Texas Tech University.

Paterson et al. ${ }^{7}$ conducted a survey of faculty who serve as advisors for student chapters of EWB-USA, the American Society of Civil Engineers (ASCE), or the American Society of Mechanical Engineers (ASME). About 100 responses were received (representing about 30\% of the EWB-USA student chapters and only $6 \%$ of the ASCE/ASME chapters). Results found that about $40 \%$ of the universities had courses with SL projects; most created within the past 5 years (69\%), targeted to juniors and seniors, with about 20 students per course, and incorporating EWB in some fashion. Most faculty felt that LTS provided strong and diverse learning outcomes for students. There was also general consensus regarding the reality of costs (negatives) associated LTS programs: time, money, and promotion/tenure (P\&T). Among the EWB faculty advisors, most were advisors for 3-4 years, across a broad range of seniority ( $<5$ to $>20$ years as faculty members), and $73 \%$ reported spending 2 or more hours/week on their EWB advising activities (10\% spent more than 8 hours / week).

In a large study by Abeset al. ${ }^{18}$, a survey of more than 500 faculty across 29 diverse colleges and universities found that the factors that motivate and deter faculty from using SL were fairly consistent between the faculty who do and do not teach via SL. The only statistical differences were in attitudes about the importance of research and publication (higher among non-SL faculty) and the personal importance of professional service (higher among SL faculty). The most important "encouragement" factor in the decision to use SL was students (rated 3.41) over community members (3.20), department chairperson (3.09), faculty in department (3.08), president of university (2.92), college dean (2.87), or faculty in another department (2.91) [rating scale: $4=$ very important, $3=$ important, $2=$ somewhat important, $1=$ not important]. Among faculty who use SL, student learning outcomes $(3.70 ; 69.5$ frequency) were more important than community outcomes $(3.11,38.6$ frequency), with little importance of professional responsibilities (19.0 frequency). The factor that potentially deterred the continued use of SL were most commonly cited as time intensive (39\%) and difficulty coordinating community service ( $25 \%$ of male respondents); only $17 \%$ indicated lack of reward in P\&T / performance reviews as a deterrent. However, in an interesting departure by discipline, $40 \%$ of the faculty in math, engineering, and computer science ALSO indicated that they were unsure that students benefited (vs. $31 \%$ of business faculty and $<25 \%$ for all other disciplines). The factors that were most significant in deterring non-SL faculty from trying SL were: anticipated logistical problems (3.23), unsure how to use SL effectively (3.18), not relevant to the courses they teach (3.11), and lack of release time to develop an SL course (3.08) [rated on 1 to 5 Likert scale]. Lack of course relevance was particularly a concern for math, engineering, and computer science faculty.

The data about what concerns faculty about LTS provides an incentive to develop strategies to help faculty address these issues. Therefore, a summit was held to gather advice from experienced faculty and staff on how to most effectively design, manage, and assess LTS in engineering. This information should be helpful both to faculty who are considering engagement with LTS and faculty who currently practice LTS and are interested in improving their programs and/or being more efficient. 


\section{Summit}

Individuals with a background teaching engineering via LTS, administering engineering LTS programs, and/or researching LTS were invited to participate in a 2-day summit in Fall 2011. The participants in the summit included 24 faculty,five faculty/staff members from the research team (four who generally participated in the activities and one who primarily facilitated) and five graduate students/post-doctoral researchers from the team (who primarily observed and handled logistics). The majority of the participants had significant experience with engineering LTS, either via teaching SL courses, advising student extracurricular service projects, and/or coordinating LTS programs. A smaller group of individuals with strong assessment experience (primarily from outside engineering) also participated. The faculty participants ranged in rank from assistant to full professors, department chairs, and associate deans. These individuals represented a diverse range of engineering disciplines (biological, biomedical, civil, environmental, materials, mechanical) and came from a range of academic settings from private colleges to large public universities (including Carnegie Classifications ${ }^{19}$ of Bac/Diverse, M/L, DRU, RU/H, RU/VH). Thirty-three percent of the participants were female.

\section{What excites faculty about LTS?}

The first exercise of the summit was to share with the entire group what each individual found personally exciting about LTS. Participants often had many thoughts, and therefore tried to avoid repeating an idea that had already been shared. The ideas shared were transcribed, and then turned into the image below which reflects the frequency that different words were used (using www.wordle.net). Most of the faculty commented about the positive impacts of LTS on students - their learning, motivation, passion, excitement, leadership, and change to be better engineers. Twenty-one of the 28 people shared an idea that included student impacts. Faculty were also excited about the potential for positive impacts on communities; 9 of the 28 ideas included this element at their core. From these initial comments it appeared that studentcentered benefits were most prominent as a motivator for faculty members. 


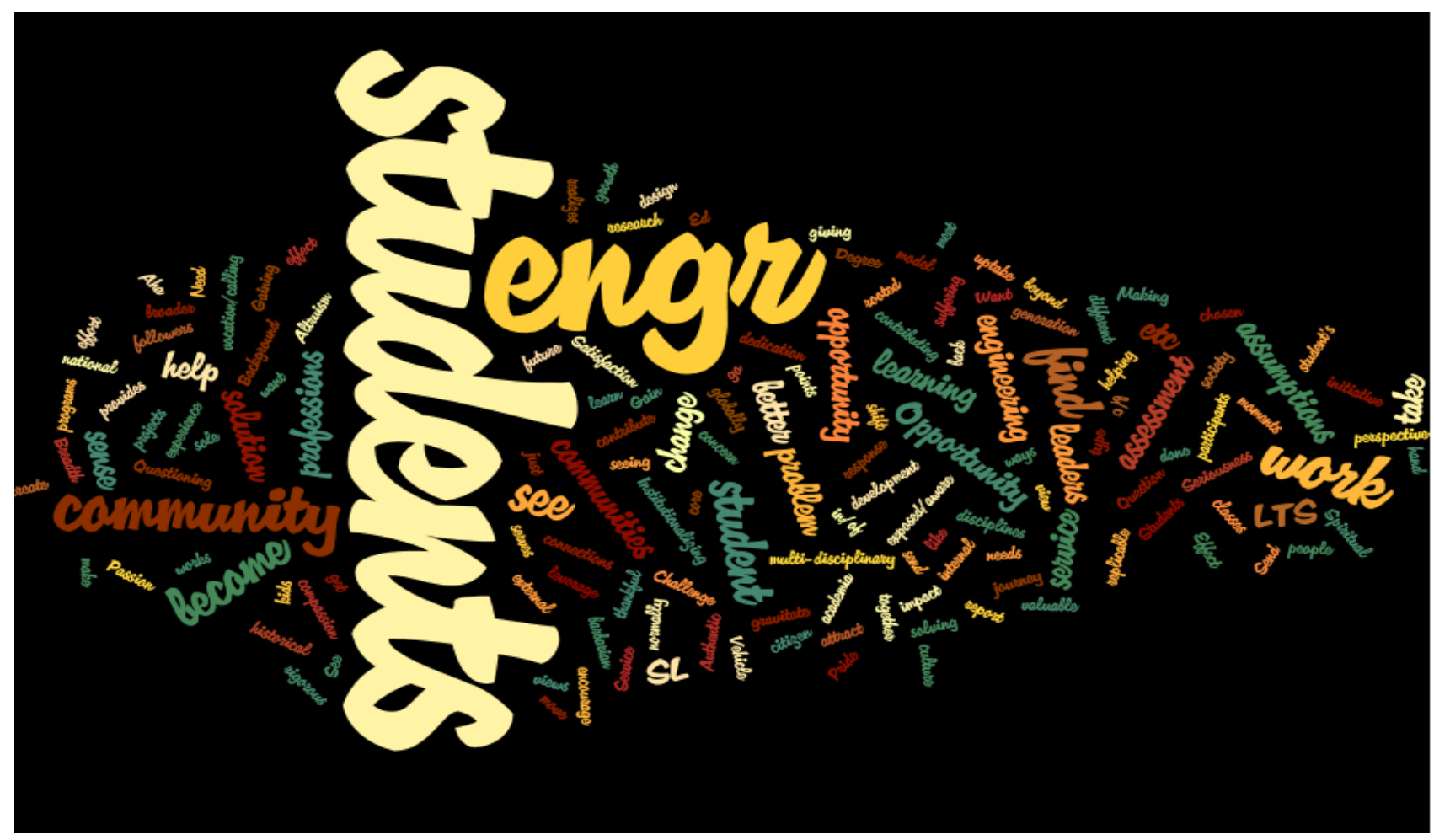

Figure 1.Wordle of faculty statements on what excites them most about LTS

\section{Affinity Mapping}

Next, the summit participants conducted individual brain-storming followed by group affinity formation exercises. This followed closely with the KawakitaJiro (KJ) method. ${ }^{20}$ This involved: (1) posing a question or series of questions for the large group to individually consider, and write their ideas on sticky-notes; (2) post their ideas on the appropriate "question board"; (3) subgroups then cluster the ideas into similar themes; (4) the sub-groups name the themes and conduct additional evaluation (such as ranking importance, determining inter-relationships, etc).

The overall structure of the questions explored is shown in Figure 2 below. The questions that participants considered required them to consider LTS program design, management, and assessment from the perspectives of best practices, benefits, and obstacles/pitfalls. For example, the best practices questions were: (1) What LTS program design attributes are critical? (2) What LTS program management attributes are critical? (3) What LTS assessment attributes are critical? These questions were considered from four different perspectives: faculty, university, students, and community. 


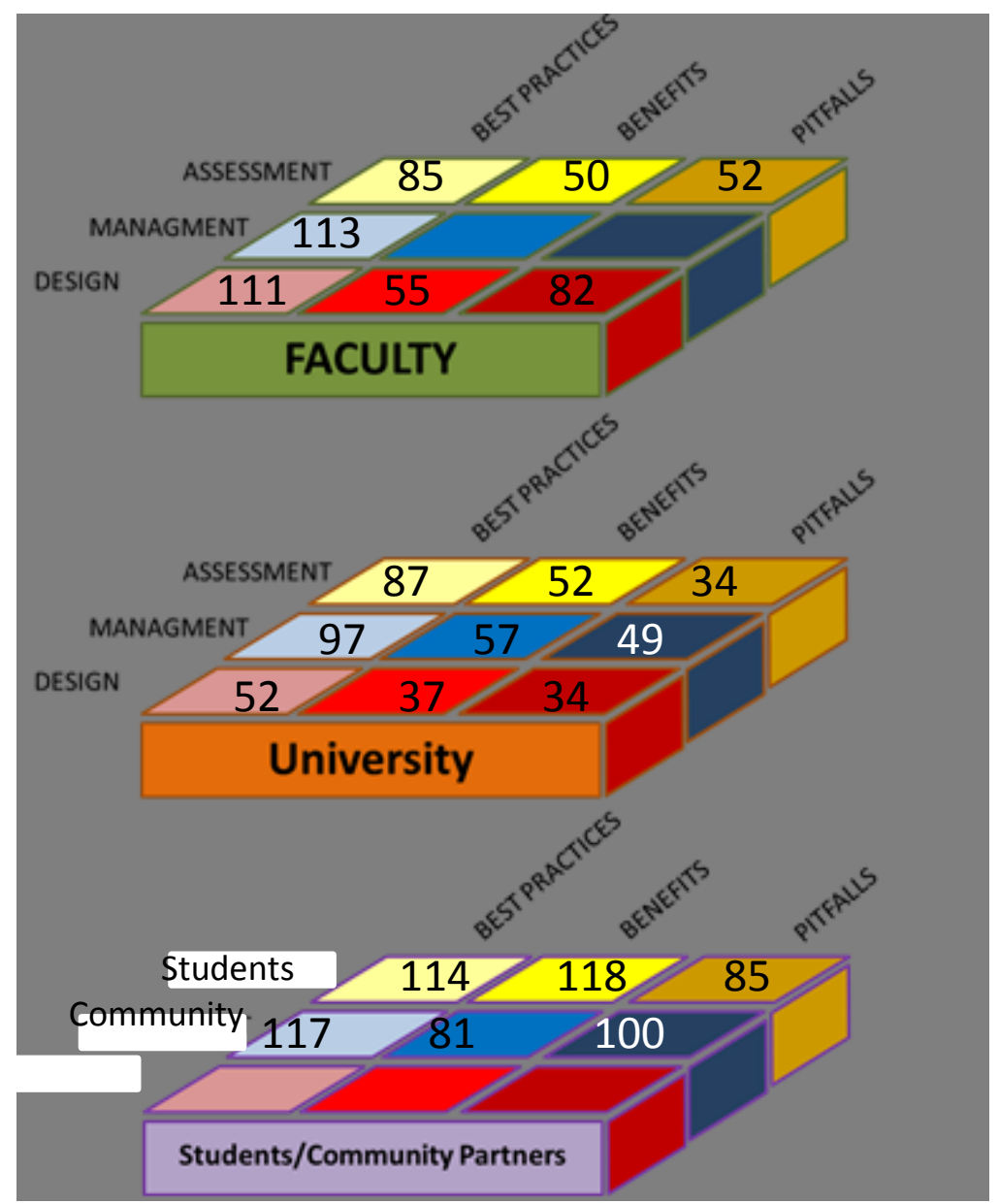

Figure 2. LTS Questions Considered in the Affinity Mapping

The cycles of individual idea generation followed by group distillation were repeated until all of the areas on the LTS concept map were covered. This paper will focus on the faculty perspective (the top block of the deconstructed Rubik's cube in Figure 2). The number of different participant ideas (ie. Post-it notes) within each topic area are also shown in Figure 2 for each subcategory within a given perspective. In most cases, best practice ideas outweighed benefits and obstacles, which were about equal.

Table 1 below summarizes the themes that emerged on each topic from a faculty perspective. From this summary, it is clear that many issues could be found as best practices, benefits, and/or obstacles. Highlighting was added to the table to focus attention on these common areas, where the same color highlights a similar idea. First, student, faculty, and community issues were not confined to that specific "lens" of focus. Faculty training and development was an important concern, in order to train faculty to design, manage, and assess LTS. This issue has not received significant attention in previous LTS studies. The impacts of LTS on promotion and tenure (P\&T) were key issues. There were potential benefits to the P\&T process, but more often there was concern that time and attention devoted to LTS might detract from time on research and would not be rewarded in the P\&T process. This concern was has been previously documented. ${ }^{7,18}$ Building strong and reciprocal partnerships with communities, facilitated by communication and listening is critical. Time, money, and other resource issues were also 
critical elements, as has been found by others. ${ }^{7,16,18}$ Best practices indicated ways to anticipate and minimize problems associated with these areas. Rigorous assessment associated with LTS activities was deemed critical, and something that should be designed into the process at the beginning. However, there was also a sense that most faculty lack the training to develop appropriate and rigorous assessment. These assessment issues have not received significant attention in previous work on faculty perspectives. Some of these and other critical themes that are summarized in Table 1 are discussed in more depth in later sections of this paper.

Table 1.Summary of the major themes of LTS from a faculty perspective (superscripts represent the number of individual brainstormed ideas that fit the theme)

\begin{tabular}{|c|c|c|c|}
\hline & Best Practices & Benefits & Obstacles / Pitfalls \\
\hline \multicolumn{4}{|c|}{ FACULTY PERSPECTIVE } \\
\hline Design & $\begin{array}{l}\text { Program features } \\
\text { Student learning/ABET } \\
\text { Multi-disciplinary }^{12} \\
\text { Institutional leadership } \\
\text { Promotion/Tenure issues }^{12} \\
\text { Impact on faculty }^{10} \\
\text { Resources }^{8} \text { Training faculty }^{8} \\
\text { Community }^{6} \text { Faculty philosophy }^{6} \\
\text { Logistical support }^{4}\end{array}$ & $\begin{array}{l}\text { Personal benefits } \\
\text { Teaching }^{11} \\
\text { Research }^{8} \\
\text { Sustain. community. dev }{ }^{7} \\
\text { Professional recognition }{ }^{5} \\
\text { Leadership opportunities }^{4} \\
\text { Adventure }^{3} \\
\text { ABET }^{3}\end{array}$ & $\begin{array}{l}\text { Peer attitudes } \\
{ }^{21} \\
\text { Time }^{16} \\
\text { Resources }^{11} \\
\text { Student engagement }^{9} \\
\text { Assessment }^{7} \\
\text { Training }^{5} \\
\text { Community partners }^{5} \\
\text { Legal and liability }^{4} \\
\text { Burn out }^{3} \\
\text { Public relations (PR) } \\
{ }^{1} \\
\text { Rigid curricula }^{1}\end{array}$ \\
\hline Management & $\begin{array}{l}\text { Attitudes } \\
\text { Advocacy/marketing } \\
\text { Resources (staff, budget) } \\
\text { Logistics } \\
\text { Curriculum } \\
\text { Risk Management } \\
\text { Faculty training / recruiting }\end{array}$ & & See best practices (opposites) \\
\hline Assessment & $\begin{array}{l}\text { Use proven assessment tools }{ }^{12} \\
\text { Integrate assessment w/ teaching }{ }^{9} \\
\text { Faculty self-development }{ }^{9} \\
\text { Assess project as scholarship }{ }^{9} \\
\text { Assess beyond ABET/students }{ }^{7} \\
\text { Time requirements }{ }^{7} \\
\text { Administrative support of process }{ }^{6} \\
\text { Measure change in quality of } \\
\quad \text { outcomes }{ }^{6} \\
\text { Learning objectives stated }{ }^{5} \\
\text { Assessment a systematic project }{ }^{5} \\
\text { Relationship to discipline }{ }^{4} \\
\text { Faculty professional development }\end{array}$ & $\begin{array}{l}\text { Improve the LTS process } \\
\text { Involve LTS scholarship }{ }^{10} \\
\text { External recog. of faculty } \\
\text { Collaborate outside engr } \\
\text { Personal growth of faculty } \\
{ }^{6} \\
\text { Impact student learning } \\
\text { Personal growth of students } \\
\text { Community impact }^{3}\end{array}$ & $\begin{array}{l}\text { Lack support / recognition } \\
\text { Time consuming } \\
{ }^{11} \\
\text { Need for faculty professional } \\
\text { development }^{8} \\
\text { Denial }^{8} \\
\text { Tools not available or }^{5} \text { recognized }^{5} \\
\text { Student reluctance }^{4}\end{array}$ \\
\hline
\end{tabular}

\section{Colors used to highlight recurring themes}

Some of the ideas that were noted for the faculty perspective also were identified in the brainstorming sessions from the university, student, and/or community perspectives. For example, from a university perspective the student learning outcomes toward ABET and broader skills were cited as best practices for assessment and management and benefits of LTS, while academic rigor was also cited as a challenge. A strong community focus was also evident in the university perspective. Time, money, and the need for other resources was also a recurring theme in the university, student, and community perspectives. The most unique ideas were 
found in the community perspective, and this is one of the most poorly researched areas on LTS in the literature. The themes included the importance of communication, working to ensure reciprocal relationships, and considering sustainability elements of both the partnerships and the projects. Further analysis of the community perspective is outside the scope of the present paper, but warrants further intense study.

\section{Faculty Perspective: LTS Best Practices for Program Design and Management}

There was a very large number of LTS best practices ideas contributed by the participants (see Table 1). The best practice ideas of LTS design from a faculty perspective were grouped into two themes: program pre-requisites and program features. More specific details on the ideas that fit under each of these two themes are summarized in Table 2 below.

Table 2. LTS Program Design Best Practices

\begin{tabular}{|l|l|}
\hline Program Pre-requisites & Program Features \\
\hline Faculty rewards / P\&T / impact on faculty & Training faculty \\
Community partner & Faculty philosophy \\
Institutional leadership & Learning outcomes for students \\
Faculty philosophy & Logistical support resources \\
Training faculty & \\
\hline
\end{tabular}

Some of the program features cited as best practices include the following. First, it is important to be sure that the learning objectives (or course objectives) align with the selected service project. These inter-relationships should be clear to everyone - students, the program, and the community. The projects should also have clear deliverables agreed on by both the faculty member and the community, and that reflect academic rigor. The LTS program must be wellintegrated with the community partner, so that expectations are clear. The projects themselves should be open-ended yet guided or structured, and perhaps should incorporate hands-on construction and/or experimentation. The projects should also incorporate sustainability, including social, economic, and environmental considerations. The projects should include both high profile social entrepreneurship and low tech short term projects; this combination may attract a diversity of faculty and sustained interest. If an LTS program is to be sustained long term, it should not be dependent on a single faculty member. Vertically integrated teams have been successful, i.e. EPICS. There was a sense that broader integration of LTS throughout a curriculum or via a certificate/minor was desirable. Finally, thoughts regarding whether LTS should be voluntary (extracurricular and elective courses) or mandatory (within required courses) was unclear, but these issues were believed to impact the commitment of the students and their buy-in.

There was a sense that engineering faculty need to be better trained to:

1) develop effective LTS approaches,

2) mentor and manage LTS projects rather than lecture,

3) advise students effectively,

4) prepare faculty for resistance from some students, and

5) further develop teamwork skills. 
It was also important to educate and inform faculty on the benefits of involvement with LTS and how to link this to their research and requisite promotion and tenure (P\&T) metrics. Further, faculty philosophy played a role. Faculty involved in LTS typically believe education is a process not a product, view engineering as more than technical, are hands-on and accessible to all constituencies with respect to the LTS program, and have a breadth of experience. Faculty cannot be forced to participate in LTS, but must be willing to invest the time and care necessary to make the program / project successful.

Institutional leadership was also stated to play a role. The LTS program must fit the mission of the department, college, and/or university. Institutional culture will play a role in this fit, and determine whether LTS becomes part of the fabric of the institution. The program must plan to demonstrate its success to Deans, Administrators, and community partners. These success metrics and stories will be needed to garner the necessary institutional support in term of sufficient allocation of money, staff, time (endorse faculty time investments), and liability. They should support and provide incentives for faculty to embrace SL, and allow these activities to "count" as part of their normal teaching and research responsibilities. Finally, it was noted that the institutional leadership can encourage faculty to shift from a "what's taught" orientation to a "what's learned" focus.

LTS management best practices weresomewhat related to LTS design. In this case the group distilled its thoughts into a synthesized whole, rather than simply clusters of the individual ideas; see Figure 3. First, management aspects of an LTS program were considered. The program should build important attitudes such as understanding the relation of engineering to society, altruism, and a pro bono mindset. Case study examples can be provided of successful faculty that integrated LTS into their career. To partner with the community, time and energy must be invested in relationship building. An intermediary may help assist this process. It is important to maintain community engagement, and for university students, staff, and faculty to recognize and value the indigenous knowledge in the community. Resource requirements were also mentioned; there may be low start-up requirements but an endowment can help sustain an LTS program. The program should also consider advocacy and marketing of its activities and benefits. 


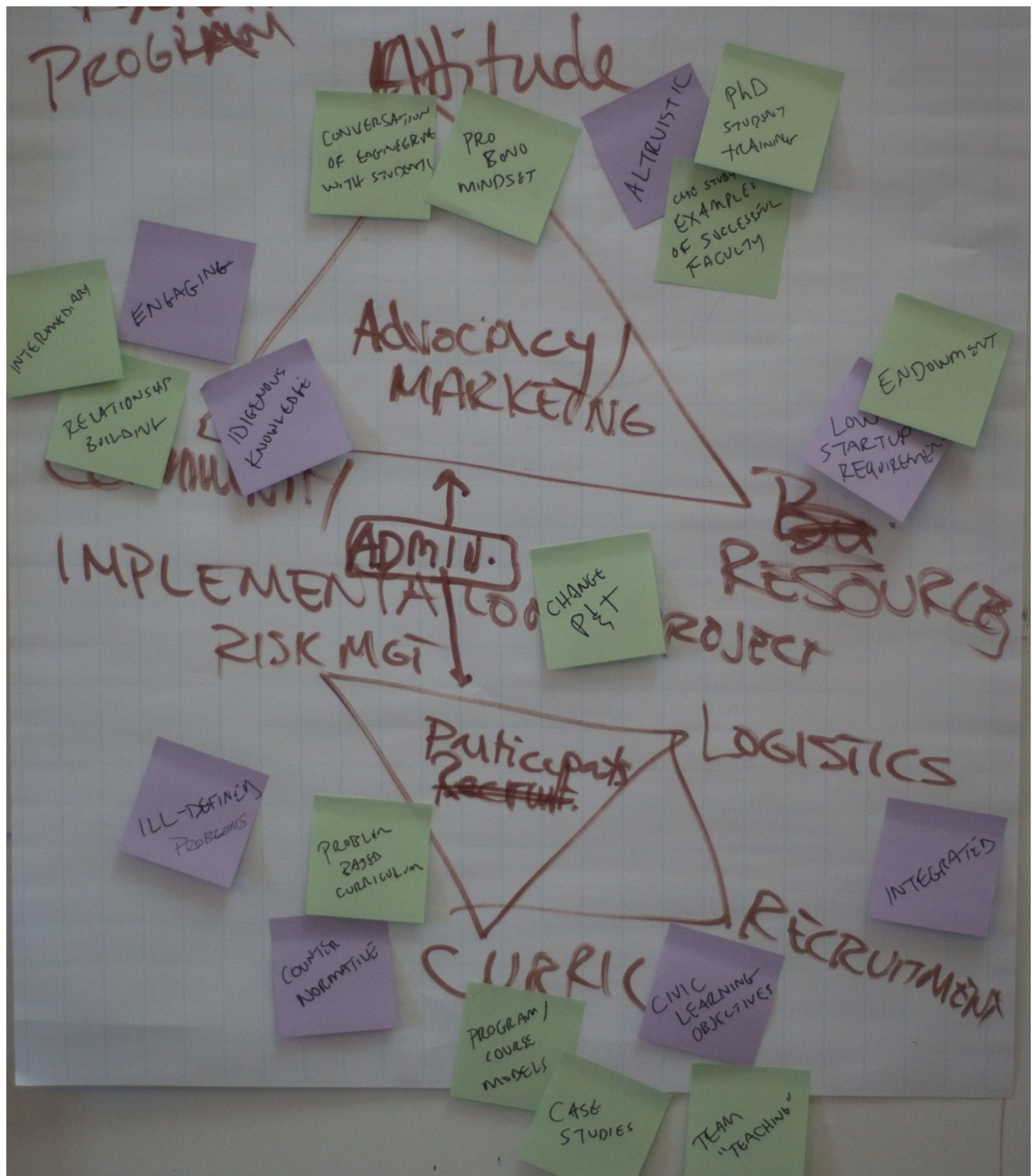

Figure 3. LTS Management Best Practices from a Faculty Perspective

Different best practices apply when managing the implementation of a specific project is considered. There needs to be an administrative bridge between the LTS program and the specific projects. Projects must consider logistics and risk management. The group recommended curricular integration of the projects. These ill-defined problems can form the basis for problem-based courses. SL projects can meet civic learning objectives. There was a 
recommendation to consider case studies of successful project implementation and team teaching strategies in the SL courses.

\section{Faculty Perspective: LTS Benefits and Obstacles of Program Design}

The benefits to faculty were grouped into two main categories: personal and professional. In the summary discussion to the group, the main points listed in each of these categories are shown in Table 3 below. Most of the issues did not appear specific to design of LTS experiences, but rather represented overall benefits that may accrue to faculty who participate in LTS.

Table 3. Benefits and Obstacles to Faculty from LTS

\begin{tabular}{|l|l|l|}
\hline Personal Benefits & Professional Benefits & Obstacles \\
\hline Adventure (travel, new & Professional recognition & Peer attitudes \\
experiences) & publicity of faculty member's work & Time \\
Delight \& personal growth & national, institutional awards (i.e. & Lack of Training \\
$\begin{array}{l}\text { Fun, challenging, rewarding, } \\
\text { motivating }\end{array}$ & teaching) & Assessment (esp. outcomes that \\
are hard to measure) \\
Sustainable community & Research & Burnout \\
development & traditional research and consulting & Cultural barriers \\
Enjoy positive impacts on & source of new research ideas & Community partners \\
communities & teaching related publications / funding & Lack of institutional support \\
Leadership opportunities & New funding opportunities & Lack of resources \\
Teaching \& students & Meeting ABET outcomes & Rigid curriculum \\
connect and build relationships \\
with students; more fun teaching \\
engaged students & Leadership opportunities (and & \\
\hline
\end{tabular}

Interestingly, the faculty perspective on LTS design was the only one of two focus topic where the obstacles noted by individual participants ( 82 ideas, some repeats) were significantly more numerous than the benefits ( 55 ideas, some repeats). This may be due to the mind-set of engineers as "problem solvers" and therefore as skilled at identifying problems. However, the group of summit participants were all actively involved in LTS, so clearly they all had personally concluded that the benefits outweighed the costs.

Some of the perceptions about the attitudes of faculty peers were the most troubling. These included actively negative ideas; statements like: “you're not a real engineer!", leadership who believe this [LTS] isn't "real teaching", not considered "rigorous", what is all this touchy-feely stuff, sometimes not considered engineering, loss of respect of peers, viewed with mistrust by other faculty. Clearly some LTS faculty have received this feedback from peers. However, it is unclear to what extent these issues stem from a vocal minority or do in fact represent a common attitude among most engineering faculty. It is also unclear the extent to which this is a problem with "old guard" engineering faculty. Other ideas communicated more of a sense of the difficulty getting more faculty to buy-in, such as: convincing faculty, other faculty who don't get it, convincing peer faculty of benefits.

These general feelings were then quantified into difficulties in the P\&T process, and the lack of a suitable faculty reward structure. An inter-related concern appeared to be the idea that time invested in LTS might take away from time devoted to activities deemed more important in the 
P\&T process. For course-based SL this might reflect the broader problem of under-valuing teaching, which is common at some research-intensive institutions. In general, project based learning (PBL) may be more time-intensive for faculty than lectures. This is particularly true in capstone design. However, capstone design is already time-intensive for faculty and it is unclear if using SL projects instead increases this time burden.

Time invested in extracurricular LTS would be invested toward service load, butsome faculty have also found that even course-based SL is "counted" under service rather than teaching, which is typically less valued overall [i.e. most institutions base yearly evaluations on $40 \%$ research, 40\% teaching, and 20\% service]. Extracurricular LTS such as EWB that may require international travel causes additional impacts on balancing personal and family time against professional responsibilities. These issues are important and valid concerns. Anticipating these attitudes from other faculty and creating strategies to address them may help defuse some of these problems. The best practices ideas may also help minimize these potential problems associated with LTS.

\section{Faculty Perspective: Assessment}

The group felt that engineering LTS assessment best practices may not yet be available. Overall many engineering faculty are poorly trained in assessment that extends beyond grading and measurement of students'content-based knowledge.For faculty outcomes, assessment should include both professional development and self development aspects. From the professional development side, faculty must be able to distinguish between assessment of LTS and LTSrelated research. A good practice is to align assessments with university goals, and student outcomes that encompass both the ABET A-K and broader outcomes. Community assessment was believed to be one of the weakest elements of LTS activities.

The ranked list of best practices in assessment (top = most important) were:

- Assess a variety of outcomes beyond ABET (a)-(k) and student learning

- Most of these were community impacts, assess social justice in service projects, articulate objectives from a community perspective and assess these benefits

- Learning objectives should be clearly stated - define success, begin design of an LTS program starting from the learning objectives

- Integration of assessment with teaching and learning - including both student and faculty reflection, make it easy to administer, embedded assessment preferred

- Assessment must result in improvement

- Faculty self-development (internal/personal)

- Understanding of time requirements for assessment - student/faculty

- Assessment is a systematic project

- Administration support of the assessment process

- LTS professional development for faculty

- Relationship to discipline

- Assessment of project as scholarship

- Use of recognized/proven assessment tools (pre \& post, focus groups, etc.)

- Align assessment with institutional process

- How are faculty assessed? Vs. How are students assessed? 
- Scholarly value of faculty's work to assess SL

The benefits of assessment from a faculty perspective were ranked from most to least important as:

- Understand Community impact through feedback - allows measurement of LTS impacts external to the university

- Allows for Inter-disciplinary collaboration

- Collaborating with non-engineers, i.e. education/social science faculty

- Collaborating with non-barbarians

- External recognition of faculty contribution

- Improving the LTS process

- Impact on Student Learning - compare LTS to traditional teaching, evaluate if learning objectives are being met

- Involvement in LTS Scholarship - can publish assessment data as scholarly work, use data in $P \& T$

- Personal growth of students-see what motivates students, students see public value in their work

- Personal growth of faculty-faculty becoming more intentional in their teaching, question the value of your teaching, understand different kinds of learning

In addition to assessment benefits, an approximately equal number of assessment obstacles were identified. However, these were not ranked by the group. Some of the ideas were:

Lack of support and recognition - a culture of non-assessment, assessment not valued in the profession, institutional culture only recognizes one form of assessment, lack of support for assessment

Denial - ignorance of benefits of assessment, inertia, distrust reliability of assessment results, do not want bad news, some faculty believe assessment is all about accountability Student reluctance -i.e. students asked to do too many surveys and push-back

\section{Summary and Conclusions}

Most of the faculty who participated in the LTS summit felt that they had learned lessons on how to improve LTS to maximize the benefits to faculty, the University, students, and communities. Many of these best practices had a lot in common with current thoughts on best-practices for engineering education overall (i.e. clear learning objectives, appropriate assessment, focus on what students learn rather than what is taught, open-ended projects, engineering reaching beyond technical attributes, inclusion of sustainability). However, each situation is unique and a single model cannot be guaranteed to work in all situations. In addition, knowing the path to strong LTS programs and reaching these goals are not always easy or possible. For example, resource issues related to time, staff support, and funding are on-going challenges for most programs. Strong integration of assessment activities into LTS programs and projects may help confront many challenges. Armed with data on the benefits of LTS to student learning and communities, this ammunition may help a program obtain needed resources and respect. One strong feeling from the meeting was that the community of LTS faculty in engineering needs to network, which may help bolster sometimes seemingly isolated activities. The group of summit participants had 
all made personal choices indicated that the benefits of LTS outweighed the obstacles and pitfalls. Many were passionate advocates of LTS and interested in helping to increase the number of quality of faculty engaged in LTS activities throughout engineering programs.

\section{Acknowledgments}

This work was funded via the NSF DUE program project 1022831. Any opinions, findings, and conclusions or recommendations expressed in this material are those of the author(s) and do not necessarily reflect the views of the National Science Foundation.

\section{Bibliography}

1. Swan, C.W., J.J. Duffy, K. Paterson, A. Bielefeldt, O. Pierrakos. 2011. The EFELTS Project - Engineering Faculty Engagement in Learning Through Service. American Society for Engineering Education (ASEE) Annual Conference Proceedings. Paper AC 2011-1324.

2. Eyler, J., D. Giles. 1999. Where's the Learning in Service-Learning? Jossey-Bass, San Francisco.

3. Coyle, E. J., L. H. Jamieson and W.C. Oakes, EPICS: Engineering Projects in Community Service, International Journal of Engineering Education, 21 (1), 2005, pp. 139-150.

4. Duffy, J., E. Tsang, S. Lord. 2000. Service-Learning in Engineering: What, Why, and How? American Society for Engineering Education (ASEE) Annual Conference Proceedings, Session 3630, 9 pp.

5. Bielefeldt, A.R., K. Paterson, and C. Swan. 2009. "Measuring the Impacts of Project-Based Service Learning." American Society for Engineering Education (ASEE) Annual Conference and Exposition Proceedings.Paper 20091972.June 24-17, Austin, TX.

6. Duffy, J., D. Kazmer, L. Barrington, J. Ting, C. Barry, X. Zhang, D. Clark and A. Rux (2007). Service-learning integrated into existing core courses throughout a college of engineering, American Society for Engineering Education (ASEE) Conference and Exposition Proceedings, Paper 2007-2639, 34 pp.

7. Paterson, K., C. O'Holleran, C. Leslie. 2010. Faculty Impressions of Service Learning in Engineering Education. American Society for Engineering Education (ASEE) Annual Conference and Exposition Proceedings.Paper 2010$2033.9 \mathrm{pp}$.

8. Bielefeldt, A.R., M.M. Dewoolkar, K.M. Caves, B.W. Berdanier, and K.G. Paterson. 2011. Diverse Models for Incorporating Service Projects into Engineering Capstone Design Courses. International Journal of Engineering Education, 27(6) 1206-1220.

9. Bielefeldt, A.R., K.G. Paterson, and C.W. Swan. 2010. Measuring the Value Added from Service Learning in Project-Based Engineering Education. The International Journal of Engineering Education. 26 (3): 535-546.

10. ABET (2010). Criteria for Accrediting Engineering Programs Effective for Evaluations During the 2011-2012 Accreditation Cycle, ABET Engineering Accreditation Commission. www.abet.org

11. Jaeger, B., E. LaRochelle. 2009. EWB^2 - Engineers Without Borders: Educationally, A World of Benefits. American Society for Engineering Education (ASEE) Annual Conference Proceedings.Paper AC 2009-740, 23 pp. 
12. Duffy, J., L. Barrington, M. Heredia. 2009. Recruitment, Retention, and Service-Learning in Engineering.American Society for Engineering Education (ASEE) Annual Conference Proceedings.Paper AC 2009$2138,27 \mathrm{pp}$.

13. Bielefeldt, A.R. 2006. Attracting Women to Engineering that Serves Developing Communities.American Society for Engineering Education (ASEE) Annual Conference Proceedings.June 19-21, Chicago, IL.

14. Burack, C., J. Duffy, A, Melchior, and E. Morgan (2008). Engineering Faculty Attitudes Toward ServiceLearning. American Society for Engineering Education (ASEE) Annual Conference Proceedings.Paper AC 20081521.

15. Duffy, J., L. Barrington, C. West, M. Heredia, C. Barry. 2011. Service-Learning Integrated throughout a College of Engineering. Advances in Engineering Education. 2 (4), 23 pp.

http://advances.asee.org/vol02/issue04/media/09-media01-App-E.pdf

16. Banzaert, A., S. Ariely, D. Wallace, B. Masi. 2005. Faculty views of service learning in mechanical engineering at MIT. American Society of Engineering Education Annual Conference Proceedings.12 pp.

17. Fontenot, A.D. Engineering Faculty Resistance to Integrating Service Learning in Courses. American Society for Engineering Education (ASEE) Annual Conference Proceedings.Paper AC 2008-1115.

18. Abes, E.S., G. Jackson, S.R. Jones. 2002. Factors that motivate and deter faculty use of service-learning. Michigan Journal of Community Service Learning. Fall, 5-17.

19. Carnegie Foundation for the Advancement of Teaching. Classification Description.Basic Classification.http://classifications.carnegiefoundation.org/descriptions/basic.php Accessed Jan. 11, 2012.

20. Ulrich, K. 2003. KJ Diagrams.http://opim.wharton.upenn.edu/ ulrich/documents/ulrich-KJdiagrams.pdf Accessed Jan. 11, 2012. 